\title{
Effects of Denture Cleansers on Candida albicans Biofilm and Physical Property of Denture Base Materials
}

\author{
Min-Young Ko', Ja-Won Cho', Hyun-Jun Yoo', Myung-Gu Lee ${ }^{2}$, Yeol-Mae Jeon ${ }^{1}$, Da-Hui Kim², \\ Sung-Gin Kim ${ }^{1}$ \\ ${ }^{1}$ Department of Preventive Dentistry, College of Dentistry, Dankook University, Cheonan, ${ }^{2}$ Department of Biomedical \\ Chemistry, College of Biomedical \& Health Science, Konkuk University, Chungju, ${ }^{3}$ Department of Dental Hygiene, College of \\ Health Science, Dankook University, Cheonan, Korea
}

Objective: This study was to investigate and compare the antifungal activity of commercial denture cleansers sold in Korea against C. albicans biofilms and to analyze changes induced in the physical properties of denture base acrylic resin, by denture cleansers.

Methods: A specimen of denture base material was fabricated using polymethylmethacrylate acid for the formation of $C$. albicans and physical analysis. C. albicans biofilm was formed on the denture base acrylic resins using Ham's F-12 medium in a 5\% CO2 incubator. The biofilms were treated with denture cleansers such as ClinicDent, DENTFIX, Polident ${ }^{\circledR}$, and Good Habit according to the manufacturer's instructions, and the suspension of C. albicans was inoculated on an agar plate after disrupting the biofilm. The denture base acrylic resins were treated with denture cleansers for 90 days, and surface roughness, surface hardness, and color change were analyzed using an atomic force microscope, Vickers microhardness device, and colorimeter, respectively.

Results: Polident ${ }^{\circledR}$ and Good Habit showed the strongest antifungal activity against C. albicans biofilm, and DENTFIX showed the weakest antifungal activity against the biofilm, compared to the others. The denture cleansers used in this study significantly increased the surface roughness of the denture base acrylic resins $(p<0.05)$. Polident ${ }^{\circledR}$ and Good Habit-treated resins showed significantly less surface hardness compared to that of the control $(p<0.05)$.

Conclusion: No significant differences were observed in terms of physical changes among the denture cleansers-treated denture base acrylic resins. Polident ${ }^{\circledR}$ and Good Habit had stronger antifungal activity against C. albicans biofilm than the other cleansers. Based on the results, Polident ${ }^{\circledR}$ and Good Habit are suitable for use among denture wearers.

Keywords: biofilm, Candida albicans, denture cleansers, denture base materials

\section{Corresponding author Sung-Gin Kim}

E-mail: dkuprev@gmail.com

(iD) https://orcid.org/0000-0003-4115-8165

Received July 15, 2021, Revised September 27, 2021, Accepted September 29, 2021

*This article is an excerpt from Min-Young Ko's 2020 doctoral thesis.

\section{Introduction}

As the elderly population increases, the use of dentures is also increasing, accompanied by growing awareness regarding the importance of dental hygiene. Denture stomatitis is one of the most common oral disorders in removable-denture wearers [1]. Furthermore, the occurrence of denture stomatitis

Copyright (C) 2021. Korean Academy of Preventive Dentistry. All rights reserved.

This is an Open Access article distributed under the terms of the Creative Commons Attribution Non-Commercial License (http://creativecommons.org/licenses/ by-nc/4.0) which permits unrestricted non-commercial use, distribution, and reproduction in any medium, provided the original work is properly cited. 
is closely related to Candida albicans [2]. To remove the microbes on the denture surface, denture cleansers have been used.

Candida species are oral commensals present in up to $90 \%$ of healthy individuals, and C. albicans was identified in approximately $80 \%$ of the isolated Candida species $[3,4]$. This fungus is associated with mucous membrane infection as well as oral stomatitis [5,6]. C. albicans is characterized by changes in morphology and grow either as a budding yeast (blastoconidia) or as hyphae according to growth conditions $[7,8]$. The yeast cells develop to hyphae in the presence of serum at $37^{\circ} \mathrm{C}$. Interestingly, the hyphae form is maintained for a short term in the liquid condition and for long term in the solid condition [9]. In addition, the morphological change between blastoconidia and the hyphal form is regulated by interaction with the microbiological flora [10]. The hyphal form of C. albicans can invade solid materials. Therefore, one of the major factors affecting the virulence of $C$. albicans is changeable morphology in adapting to the environment, attachment to the surface, and communication between species. Another characteristic of C. albicans is the formation of biofilms in the oral cavity. C. albicans biofilms are frequently detected on denture materials, and their prevalence has been reported to be $11 \%-67 \%$ in complete denture wearers $[11,12]$. When C. albicans attaches to denture wear and forms a biofilm, it develops from blastoconidia to the hyphae form. The hyphal Candida swallows and penetrates into the pores of denture wear [13], ultimately surviving as an opportunistic pathogen in denture wearers.

Polymethylmethacrylate (PMMA), which is known as acrylic resin, is the most widely used denture base-material for removable dentures and intraoral maxillofacial prostheses because of its favorable working characteristics, such as ease of processing, accurate fit, and stability. In addition, the prosthetics made of acrylic resin are characterized by good color stability and superior esthetics and are inexpensive [14,15]. Despite their advantages, acrylic resins have some weaknesses, such as susceptibility to discoloration and changes in surface roughness [16,17]. Furthermore, the major disadvantage of acrylic resin is its susceptibility to microbial colonization in the oral cavity. Therefore, to reduce the levels of microbes on the denture surface, denture wearers use denture cleansers and antibacterial denture creams for hygiene.

Commercial denture cleansers are classified into the following groups according to their main components and their mode of action: neutral peroxides with enzymes, enzymes, acids, crude drugs, and oral rinses [18]. Denture cleansers commonly used are effervescent tablets and immersion types. Effervescent tablets, including alkaline peroxide, which releases oxygen bubbles in water, result in both mechanical and chemical cleaning actions to eliminate microbial biofilms [19]. Although dental cleansers are needed to remove microbes on their surfaces, cleansers can change the physical properties of denture wear. Various studies have reported that the daily use of denture cleansers can affect the physical and mechanical properties of denture base materials [20-23]. Furthermore, denture cleansers, including sodium hypochlorite, bleach acrylic resin dentures [24,25].

The purpose of this study was to investigate the antifungal activity of commercial denture cleansers sold in Korea against C. albicans biofilms and to examine the effect of cleansers on the physical properties of dentures.

\section{Materials and Methods}

\section{Preparation of denture base material}

A specimen fabricated using acrylic resin, which formed the main skeleton of the removable denture, was used in this study. Specimens of polymethylmethacrylate (PMMA) (Lucitone $199^{\circledR}$, Dentsply International, York, PA, USA) were processed according to the manufacturer's instructions. The disk-shaped wax template was flasked with a Type III dental stone (Snow Rock Dental Stone, DK Mungyo, Gimhae, Korea). After wax elimination, the PMMA powder and liquid were mixed according to the manufacturer's protocol. The resin dough was inserted into the mold, packed, and polymerized at $74^{\circ} \mathrm{C}$ for $90 \mathrm{~min}$ and at $99^{\circ} \mathrm{C}$ for $30 \mathrm{~min}$ in boiling water under pressure in a thermostatically controlled water bath (Jeio Tech Co., Daejeon, Korea). The specimens were cooled for $3 \mathrm{~h}$, following which the excess resin was trimmed. The specimens were stored in distilled water at room temperature until further use.

\section{Preparation of denture cleansers}

Four types of commercial denture cleansers were used in this study, and their characteristics are listed in Table 1. All denture cleansers used in this study were effervescent tablets.

\section{Fungal species and cultivation}

Candida albicans ATCC 10231 as a type strain was used in this study and cultured in Sabouraud dextrose broth (BD Biosciences, San Jose, CA, USA) at $37^{\circ} \mathrm{C}$ in a shaking incubator. To form a hyphal C. albicans biofilm, C. albicans was cultivated in Ham's F-12 medium (HyClone, Logan, UT, USA) at $37^{\circ} \mathrm{C}$ in a $5 \% \mathrm{CO}_{2}$ incubator.

\section{Immersion procedures}

One hundred millimeters of tap water $(100 \mathrm{~mm})$ was placed 
Table 1. Denture cleansers used in this study

\begin{tabular}{|c|c|c|c|}
\hline Product & Type & Manufacturer & Major composition \\
\hline ClinicDent & Effervescent tablet & $\begin{array}{l}\text { Jw Pharm, } \\
\text { Seoul, Korea }\end{array}$ & $\begin{array}{l}\text { Oxone, Sodium perborate, Everase 6, Sodium lauryl sulfate, Sodium } \\
\text { bicarbonate }\end{array}$ \\
\hline DENTFIX & Effervescent tablet & $\begin{array}{l}\text { Clannad, } \\
\text { Gyeonggi, Korea }\end{array}$ & $\begin{array}{l}\text { Oxone, Sodium carbonate, Sodium bicarbonate, D-sorbitol, Sodium lauryl } \\
\text { sulfate, Sodium lauryl sulfoacetate }\end{array}$ \\
\hline Polident & Effervescent tablet & $\begin{array}{l}\text { GSK Korea, } \\
\text { Seoul, Korea }\end{array}$ & $\begin{array}{l}\text { Oxone, Sodium perborate, Everase } 6 \text {, Sodium lauryl sulfate, Sodium } \\
\text { bicarbonate }\end{array}$ \\
\hline Good Habit & Effervescent tablet & $\begin{array}{l}\text { Donghwa Pharm, } \\
\text { Seoul, Korea }\end{array}$ & $\begin{array}{l}\text { Oxone, Sodium perborate, Everase } 6 \text {, Sodium lauryl sulfate, Sodium } \\
\text { bicarbonate }\end{array}$ \\
\hline
\end{tabular}

in $250 \mathrm{ml}$ glass flasks, and each denture cleanser was added to a separate flask. Candida biofilm-formed denture base acrylic resins were placed in a flask containing denture cleanser solution and incubated for 5 min (Polident ${ }^{\circledR}$ and Good Habit) or 10 min (ClinicDent and DENTFIX). After washing with filtered tap water, the specimens were incubated in tap water for $30 \mathrm{~min}$ at room temperature. All tap water used in this study was filtered through a polyvinylidene fluoride (PVDF) filter (pore size $0.22 \mu \mathrm{m}$ ) (Millipore, Billerica, MA, USA).

\section{Comparison of antifungal activity of the denture cleansers}

The specimens immersed in denture cleanser solutions were placed into each well of a 12-well polystyrene plate. Sabouraud dextrose broth $(1 \mathrm{ml})$ was dispensed into the wells containing the specimens. The Candida biofilms were disrupted with a scraper, and the fungal suspensions were transferred into $1.5 \mathrm{ml}$ tubes. After vortexing the tube, the suspension was serially diluted from 10 to $10^{6}$ fold, and $50 \mu$ of the diluted suspension was spread on a Sabouraud dextrose agar plate. The plates were incubated at $37^{\circ} \mathrm{C}$ for $24 \mathrm{~h}$, and the colonies of $C$. albicans were counted.

\section{Aging of the denture base acrylic resins by denture cleansers}

To investigate the effect of denture cleansers on the physical properties of denture base acrylic resins, the acrylic resins were stored in artificial saliva (composition shown in Table 2) at $37^{\circ} \mathrm{C}$ during the daytime and immersed in tap water at night after soaking in denture cleanser solution for $5 \mathrm{~min}$. This procedure was performed for $90 \mathrm{~d}$. In the control group, specimens were immersed in tap water without soaking in a dental cleanser solution.

\section{Investigation of surface roughness}

As surface roughness is closely related to Candida biofilm formation, aging of the denture base acrylic resins were ana-
Table 2. Composition of artificial saliva

\begin{tabular}{clr}
\hline Name & \multicolumn{1}{c}{ Compositions } & Volume \\
\hline Artificial saliva & Distilled water & $1 \mathrm{~L}$ \\
& Calcium chloride & $0.15 \mathrm{~g}$ \\
& Sodium carboxylmethyl cellulose & $10 \mathrm{~g}$ \\
& Magnesium chloride & $0.05 \mathrm{~g}$ \\
& Potassium chloride & $1.2 \mathrm{~g}$ \\
& Sodium chloride & $0.84 \mathrm{~g}$ \\
& Potassium phosphate dibasic & $0.34 \mathrm{~g}$ \\
& D-sorbitol & $30 \mathrm{~g}$ \\
\hline
\end{tabular}

lyzed using an atomic force microscope (AFM) (SPM-9700, Shimadzu, Kyoto, Japan). All analyses were performed in air with a surface sampling of $256 \times 256$ pixels. The scan size was $30 \times 30 \mu \mathrm{m}^{2}$. AFM images were analyzed using Shimadzu AFM software, which was used to calculate the root mean square of the average height and surface roughness of the resins.

\section{Investigation of surface hardness}

The surface hardness of the denture base acrylic resins was examined using Vickers microhardness test (HM-200, Mitutoyo Co., Kawasaki, Japan). The aging denture base acrylic resins were carried out in an air blow to remove the surface solvent and placed on the plate of the microhardness indentation machine. The resin was analyzed with a load of $500 \mathrm{gf}$ for $20 \mathrm{~s}$ using a pyramid-shaped diamond indenter. Three indentations were performed in different sections and areas of each object. The diagonal of the resulting indentation was observed and measured using the microscope in the machine, and the Vickers hardness number was calculated for each object.

\section{Investigation of color change}

Aging processed the denture base acrylic resins were investigated for color changes. The color change of the denture base acrylic resins was analyzed using a portable colorimeter 
(NR110, 3nh Co., Nangang, China), and the measurements were carried out according to the CIE L*a*b* system. The L*, $a^{*}$, and $b^{*}$ values are measures of whiteness or brightness, redness or greenness, and yellowness or blueness, respectively. The color change $(\Delta \mathrm{E})$ of the denture base acrylic resins was calculated according to the following formula: $\Delta \mathrm{E}^{*}=[(\Delta$ $\left.\left.\mathrm{L}^{*}\right)^{2}+\left(\Delta \mathrm{a}^{*}\right)^{2}+\left(\Delta \mathrm{b}^{*}\right)^{2}\right]^{1 / 2}$. In addition, to analyze its clinical significance, the color change levels of the denture base acrylic resins was quantified by the National Bureau of Standards $(\mathrm{NBS}=\Delta \mathrm{E} \times 0.92)$. Critical marks of color differences according to NBS are shown in Table 3.

\section{Statistical analysis}

Significant differences among sample groups were analyzed using the IBM SPSS Statistics ver. 24 software. Statistically significant differences between control and treated samples were analyzed by the Kruskal-Wallis test and Mann-Whitney U-test. Statistical significance was set at $\mathrm{p}<0.05$.

\section{Results}

\section{Comparison of antifungal activity of denture cleansers against $C$. albicans biofilm}

All four types of denture cleansers showed significant antifungal activity against $C$. albicans biofilm on the denture base

Table 3. Critical marks of color difference by NBS

\begin{tabular}{cc}
\hline Critical marks of color difference & Textile terms (NBS unit) \\
\hline Trace & $0.0-0.5$ \\
Slight & $0.5-1.5$ \\
Noticeable & $1.5-3.0$ \\
Appreciable & $3.0-6.0$ \\
Much & $6.0-12.0$ \\
Very much & $>12.0$ \\
\hline
\end{tabular}

acrylic resins $(\mathrm{p}<0.05)$ (Figure 1). In addition, as shown in Figure 1 and 2, Polident ${ }^{\circledR}$ and Good Habit exhibited the strongest antifungal effect on the biofilm, followed by ClinicDent. DENTFIX exhibited the lowest antifungal activity.

\section{Investigation of surface roughness}

The physical properties of removable dentures are also important in clinical settings. Therefore, after aging the denture base acrylic resin with denture cleansers, the physical properties were investigated. First, when the surface roughness of the denture base acrylic resins, the surface roughness among the resin-treated denture cleansers did not show a significant difference (Table 4).

After treatment with the denture cleansers for 90 days, there was no significant difference in the surface roughness of the denture base acrylic resins (Figure 3 ).

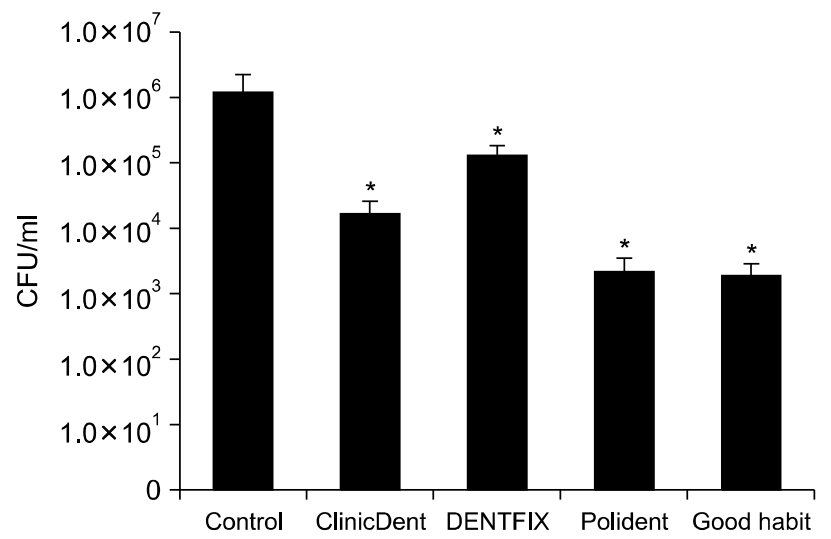

Figure 1. The comparison of antifungal activity of denture cleansers against $C$. albicans biofilm on the denture base acrylic resins. C. albicans biofilm was formed on the surface of the denture base acrylic resins, following which the resins were treated with denture cleansers. After disrupting the biofilm, the fungal suspension was spread on sabouraud dextrose agar plate and incubated. The colony forming unit was counted after incubation. *Indicates significant difference compared to control $(p<0.05)$.
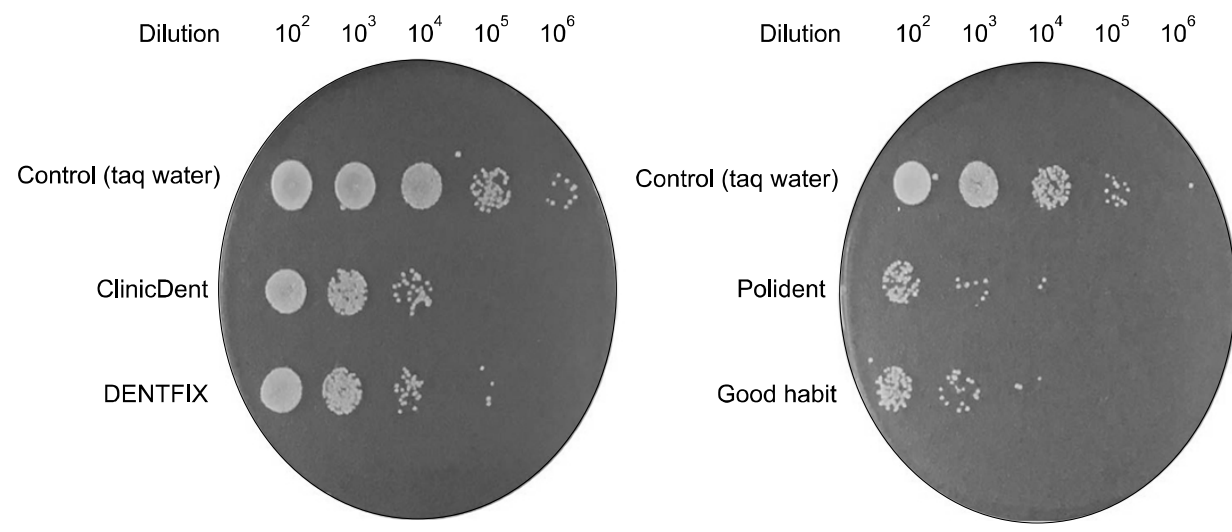

Figure 2. The antifungal activity of denture cleansers against $C$. albicans biofilm on the denture base acrylic resins. After biofilm formation, the denture base acrylic resins were treated with denture cleansers. After disrupting the biofilm, the fungal suspension was diluted 10 to $10^{6}$ -fold. Each diluted suspension was inoculated on a sabouraud dextrose agar plate. The plates were incubated at $37^{\circ} \mathrm{C}$. 
Table 4. The surface roughness of the denture base acrylic resins before and after treatment of denture cleansers

\begin{tabular}{|c|c|c|}
\hline \multirow{2}{*}{ Group } & \multicolumn{2}{|c|}{ Ra (mean \pm standard deviation) } \\
\hline & Before & After \\
\hline Control (Tap water) & $320.27 \pm 15.22 \mathrm{~nm}$ & $315.08 \pm 07.36 \mathrm{~nm}$ \\
\hline ClinicDent & $318.65 \pm 17.52 \mathrm{~nm}$ & $326.70 \pm 21.95 \mathrm{~nm}$ \\
\hline DENTFIX & $316.72 \pm 13.01 \mathrm{~nm}$ & $326.69 \pm 17.00 \mathrm{~nm}$ \\
\hline Polident ${ }^{(R)}$ & $327.34 \pm 20.20 \mathrm{~nm}$ & $325.26 \pm 10.41 \mathrm{~nm}$ \\
\hline Good Habit & $327.89 \pm 11.93 \mathrm{~nm}$ & $325.17 \pm 16.02 \mathrm{~nm}$ \\
\hline
\end{tabular}

\section{Investigation of surface hardness}

Next, the effect of denture cleansers on the surface hardness of the denture base acrylic resins was investigated. Polident ${ }^{\circledR}$ and Good Habit reduced the surface hardness of the resins more than the control, and the change in surface roughness by treatment with ClinicDent and DENTFIX was not significantly different from that of the control (Table 5).

When the surface hardness of the resins before and after treatment with all types of denture cleansers was compared, the resins exhibited a significant difference $(p<0.05)$. In par-

\section{A ClinicDent}

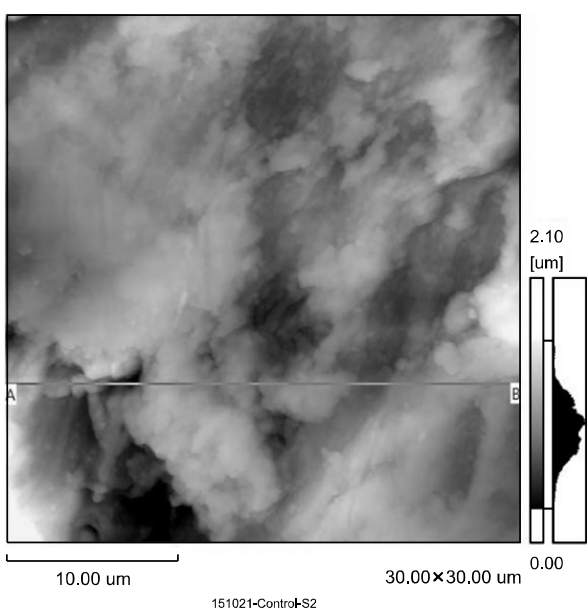

$A-B \quad 1$

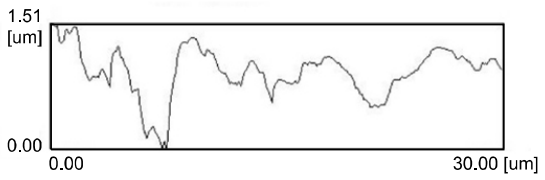

\section{Polident}

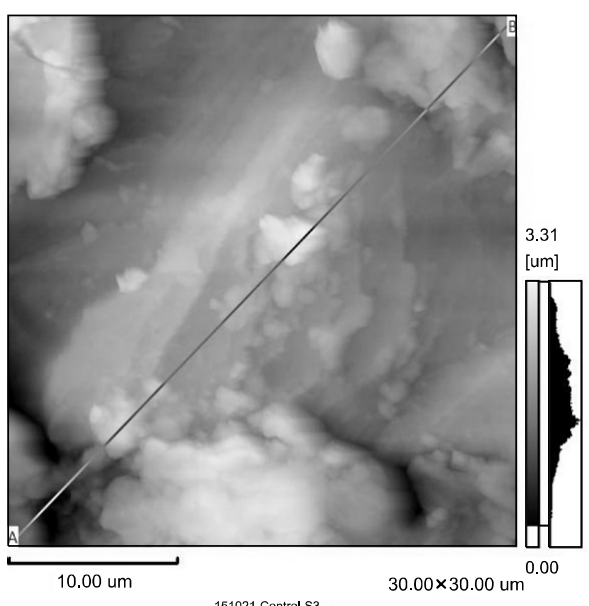

A-B $\quad 3.30$

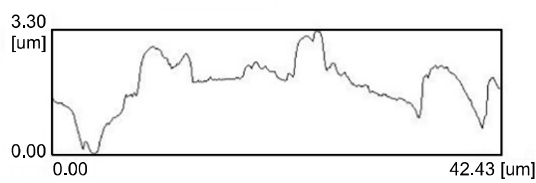

\section{B DENTFIX}

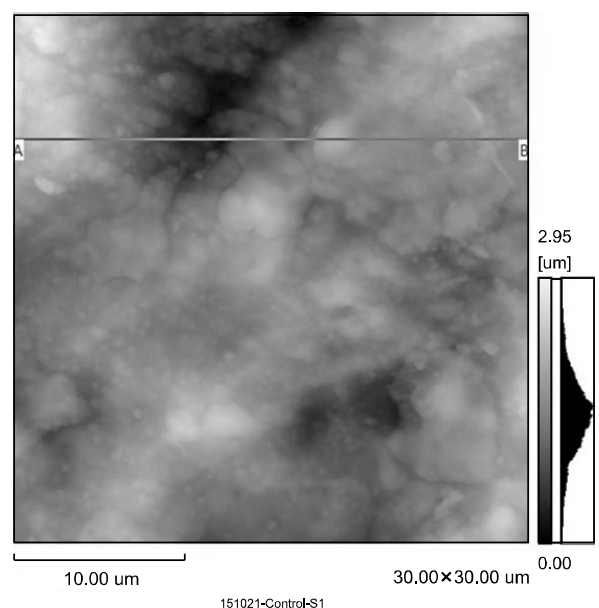

A-B $\quad 222$

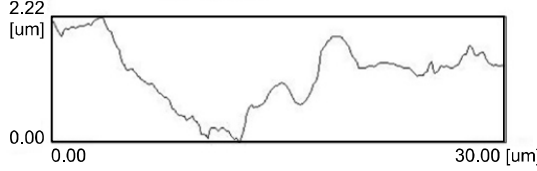

D Good habit

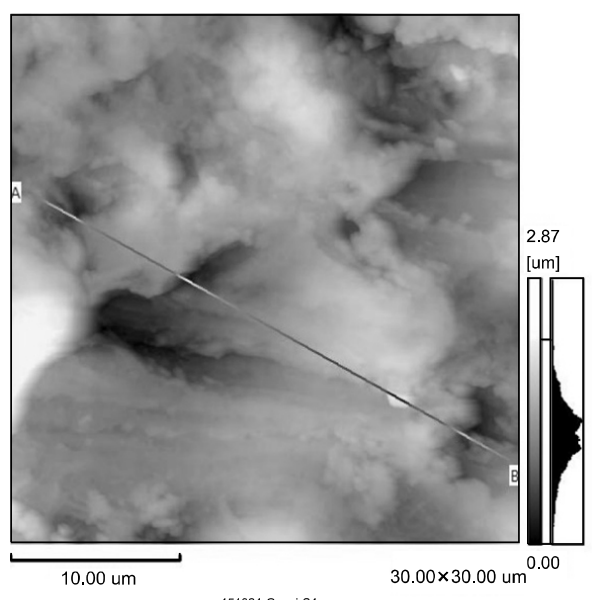

A-B

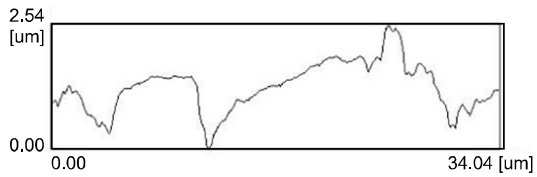

Figure 3. The image of the resin surface obtained by atomic force microscope. The denture base acrylic resins were treated with various denture cleansers for 90 days and their surface roughness analyzed with atomic force microscope. 
Table 5. The surface hardness of the denture base acrylic resins

\begin{tabular}{|c|c|c|c|}
\hline \multirow[t]{2}{*}{ Group } & \multicolumn{2}{|c|}{$\begin{array}{c}\text { Vickers hardness }(\mathrm{VHN}) \\
\text { (mean } \pm \text { standard deviation) }\end{array}$} & \multirow[t]{2}{*}{$\mathrm{p}$-value } \\
\hline & Before & After & \\
\hline Control (Tap water) & $18.51 \pm 0.19 \mathrm{~nm}$ & $17.36 \pm 0.26 \mathrm{~nm}^{*}$ & $<0.05$ \\
\hline ClinicDent & $18.65 \pm 0.29 \mathrm{~nm}$ & $17.54 \pm 0.11 \mathrm{~nm} *$ & \\
\hline DENTFIX & $18.67 \pm 0.22 \mathrm{~nm}$ & $17.44 \pm 0.28 \mathrm{~nm}^{*}$ & \\
\hline Polident ${ }^{R}$ & $18.33 \pm 0.12 \mathrm{~nm}$ & $16.76 \pm 0.23 \mathrm{~nm}^{*, \#}$ & \\
\hline Good Habit & $18.44 \pm 0.09 \mathrm{~nm}$ & $16.74 \pm 0.10 \mathrm{~nm}^{*}, \#$ & \\
\hline
\end{tabular}

*Significant difference between surface hardness before and after treatment of denture cleansers. "Significant difference compared with control.

ticular, the control group resin also showed a significant difference before and after treatment $(\mathrm{p}<0.05)$.

\section{Investigation of color change induced by denture cleansers}

Following treatment with the denture cleansers for 90 days, the resins treated with the denture cleansers showed a greater change in color compared to the control group (Table 6). There was also no significant difference in color change among the denture cleansers.

When the total color difference $(\Delta \mathrm{E})$ was converted to NBS values, the denture cleansers were observed to cause "slight changes" in color at the end of 90 days (Table 7).

\section{Discussion}

As the quality of life and medical technology improve, it is becoming an aging society. These results indicate that the use of dentures is increasing. Although dentures improve the esthetic appearance and masticatory capabilities of patients, inappropriate management of dentures leads to infectious diseases such as candidiasis. Fungal diseases can occur in elderly individuals with weakened immunity. This has generated a growing interest in dental hygiene, and the use of denture cleansers is increasing. The purpose of this study was to investigate and compare the antifungal activity of commercial denture cleansers against $C$. albicans biofilms on denture base materials. In addition, the effects of denture cleansers on the physical properties of the resins were investigated.

Immersion solutions for cleaning dentures are divided into two major groups: denture cleansers and disinfectants. In addition, commercial denture cleansers can be classified into seven types according to their mode of action or their main components, such as alkaline peroxides, neutral peroxides with enzymes, enzymes, acids, crude drugs, and mouth rinses
Table 6. Color measurement of the denture base acrylic resins after treatment with the denture cleansers

\begin{tabular}{lcc}
\hline \multicolumn{1}{c}{ Group } & $\begin{array}{c}\Delta \mathrm{E}^{*} \\
\text { (mean } \pm \text { standard deviation) }\end{array}$ & p-value \\
\hline Control (Tap water) & $0.487022 \pm 0.012846$ & $<0.01$ \\
ClinicDent & $0.600944 \pm 0.007073^{\#}$ & \\
DENTFIX & $0.598255 \pm 0.107638^{\#}$ & \\
Polident $^{\mathbb{R}}$ & $0.628932 \pm 0.065699^{\#}$ & \\
Good Habit $^{*}$ & $0.598347 \pm 0.066864^{\#}$ & \\
\hline
\end{tabular}

p-value indicates the significant difference among samples by Krusikal-wallis analysis.

${ }^{\#}$ Significant difference compared with control.

Table 7. NBS values calculated from color change of the denture base acrylic resins

\begin{tabular}{lc}
\hline \multicolumn{1}{c}{ Group } & NBS value $\left(\Delta \mathrm{E}^{*} \times 0.92\right)$ \\
\hline Control (Tap water) & 0.448060 (trace) \\
ClinicDent & 0.511257 (slight) \\
DENTFIX & 0.542534 (slight) \\
Polident ${ }^{\mathbb{R}}$ & 0.578618 (slight) \\
Good Habit & 0.550479 (slight) \\
\hline
\end{tabular}

$[19,26]$. To date, most of the denture cleansers sold in Korea are the "neutral peroxide with enzyme" type. Therefore, four "neutral peroxide with enzyme type" denture cleansers were used in this study.

Denture stomatitis is one of the most common oral disorders in removable-denture wearers [1]. In addition, denture stomatitis is related to the hyphal $C$. albicans biofilms that form on denture surfaces [13]. Therefore, in order to investigate the antifungal activity of denture cleansers, hyphal $C$. albicans biofilms were allowed to form on the denture base acrylic resins, using Ham's F-12 medium, according to the methods [27], and hyphal biofilms of C. albicans were observed with a phase contrast microscope.

Although $C$. albicans is a commensal fungus in the oral cavity, it causes mucosal diseases such as candidiasis in the elderly, people with xerostomia, and those with weak immunity $[4,28]$. In addition, C. albicans is hyphal and forms biofilms on the tongue and buccal mucosa in the oral cavity [29]. Therefore, the $C$. albicans biofilm is composed of budding yeast, pseudohyphae, and hyphae [30]. After forming biofilms, C. albicans produces various proteolytic enzymes for penetration into the tissue and production [31]. In addition, biofilms are more resistant to antifungal agents than planktonic C. albicans [32].

When the antifungal activity of commercial denture cleansers against $C$. albicans biofilms was investigated, Polident ${ }^{\circledR}$ 
and Good Habit showed the strongest antifungal activity against $C$. albicans biofilm on the denture base acrylic resins, while DENTFIX exhibited the weakest antifungal activity compared with the others. The major components of the four denture cleansers were oxon, everase 6 , sodium perborate, and sodium lauryl sulfate. Although the antifungal activity of the denture cleansers were not different with respect to their major components, they showed differences in antifungal activity against $C$. albicans biofilms on the surface of the denture base acrylic resins. These results suggest that the major components of the cleansers are the same, but there may be a difference in the major component ratio, or additional elements among the denture cleansers may differ.

Among denture base materials, PMMA is the most widely used denture base material for removable dentures and intra-oral maxillofacial prostheses because of its many advantages, such as ease of processing, accurate fit, and stability compared to other materials [33-35]. In addition, soft denture liners have not been used recently because of their disadvantages [11,36,37]. C. albicans showed more initial colonization on PMMA than on the soft liner. For these reasons, PMMA was used to form $C$. albicans biofilms, and the changes in its characteristics by denture cleansers were investigated. When the physical properties of the denture base acrylic resins after immersion in the denture cleansers was investigated, the surface roughness of the resins did not show a significant difference. Some previous studies reported that the surface roughness of PMMA acrylic resin was changed by denture cleansers of the "neutral peroxide with enzyme" type $[33,38,39]$. The difference between previous studies and this study is the immersion time and methods of denture cleansers. In this study, in order to evaluate the resin in an environment similar to the cleansers used in everyday life, the acrylic resins were stored in artificial saliva at $37^{\circ} \mathrm{C}$ in the daytime and immersed in tap water at night after soaking in denture cleanser solution for $5 \mathrm{~min}$. However, in previous studies, the denture base resins were treated with cleansers at high temperature overnight to rapidly age them. In experiments of surface hardness and color change, the denture cleansers changed the surface hardness, and the color change of the denture base acrylic resins was compared to control group that was treated with tap water. However, there were no differences in the surface hardness and color change of the denture base acrylic resins treated with denture cleansers. In the case of color change, the denture base acrylic resins showed that the range of total color difference $\left(\Delta \mathrm{E}^{*}\right)$ was 0.59 to 0.62 . When $\Delta \mathrm{E}^{*}$ was changed to the National Bureau of Standards (NBS), NBS values indicated a "slight" color change in all denture base resins at the end of 90 days. The color stability of dentures is an important factor in treatment acceptance by patients. Furthermore, it is very important for esthetic restorative materials in which the color and hardness of the materials remain stable over a long period in the oral environment [40]. The denture cleansers used in this study showed no color changes or surface hardness changes that were significantly different upon observation with the naked eye.

In conclusion, the denture cleanser that shows a strong disinfectant property and minimal physical changes on dentures is the best denture cleanser. The difference in physical changes on the denture base acrylic resins by the denture cleanser used in this study was not significant. However, Polident ${ }^{R}$ and Good Habit showed stronger antifungal activity against $C$. albicans biofilms than the other cleansers. Therefore, Polident ${ }^{\circledR}$ and Good Habit are considered suitable for use in denture wearers.

\section{Conclusion}

The number of denture wearers is increasing owing to the aging society. In addition, there is a growing interest in dental hygiene. Denture stomatitis is the most common condition in removable denture wearers and is related to Candida albicans because it is frequently detected in patients. Therefore, denture cleansers have been used to remove and prevent microbial infections. The aim of this study was to investigate and compare the antifungal activity of commercial denture cleansers sold in Korea against $C$. albicans biofilms and to analyze changes in the physical properties of the denture base acrylic resins, caused by denture cleansers.

The denture base material was fabricated using polymethylmethacrylate acid according to the manufacturer's protocols for the formation of C. albicans and physical analysis. C. albicans biofilm was formed on the denture base acrylic resin using Ham's F-12 medium in a 5\% $\mathrm{CO}_{2}$ incubator. The biofilms were treated with denture cleansers such as ClinicDent, DENTFIX, Polident ${ }^{R}$, and Good Habit according to the manufacturer's instructions, and the suspension of $C$. albicans was inoculated on an agar plate after disrupting the biofilm. Colonies were counted after incubating the plates. The denture base acrylic resins were treated with denture cleansers for 90 days, and surface roughness, surface hardness, and color change were analyzed using an atomic force microscope, Vickers microhardness device, and colorimeter, respectively.

Polident ${ }^{\circledR}$ and Good Habit showed the strongest antifungal activity against $C$. albicans biofilm, and DENTFIX had the weakest antifungal activity against the biofilm compared to the others. The denture cleansers used in this study signifi- 
cantly increased the surface roughness of the denture base acrylic resins $(p<0.05)$. In the case of surface hardness, Polident ${ }^{\mathbb{R}}$ and Good Habit significantly reduced surface hardness compared to the control group treatment $(p<0.05)$. The denture cleansers changed the color of the denture base acrylic resins more than the control group treatment did, and the difference in color changes among denture cleansers was not significant.

In conclusion, the ideal denture cleanser has effective antifungal activity and minimizes physical changes in dentures. The difference in physical change between the denture base acrylic resins treated with the denture cleansers Polident ${ }^{\circledR}$ and Good Habit had stronger antifungal activity against $C$. albicans biofilm than the other cleansers. Based on the results, Polident ${ }^{\circledR}$ and Good Habit may be suitable for use among denture wearers.

\section{Conflict of Interest}

No potential conflict of interest relevant to this article was reported.

\section{ORCID}

Min-Young Ko, https://orcid.org/0000-0002-0397-552X

Ja-Won Cho, https://orcid.org/0000-0003-1458-0416

Hyun-Jun Yoo, https://orcid.org/0000-0002-0100-8309

Myung-Gu Lee, https://orcid.org/0000-0002-0068-1438

Yeol-Mae Jeon, https://orcid.org/0000-0002-9700-9137

Da-Hui Kim, https://orcid.org/0000-0003-0226-0212

Sung-Gin Kim, https://orcid.org/0000-0003-4115-8165

\section{References}

1. Figueiral MH, Fonseca P, Lopes MM, Pinto E, Pereira-Leite T, Sampaio-Maia B. Effect of denture-related stomatitis fluconazole treatment on oral Candida albicans susceptibility profile and genotypic variability. Open Dent J 2015;9:46-51.

2. Costa F, Manaia CM, Figueiral MH, Pinto E. Genotypic analysis of Candida albicans isolates obtained from removable prosthesis wearers. Lett Appl Microbiol 2008;46:445-9.

3. Ghannoum MA, Jurevic RJ, Mukherjee PK, Cui F, Sikaroodi M, Naqvi A, et al. Characterization of the oral fungal microbiome (mycobiome) in healthy individuals. PLoS Pathog 2010;6: e1000713.

4. Coronado-Castellote L, Jiménez-Soriano Y. Clinical and microbiological diagnosis of oral candidiasis. J Clin Exp Dent 2013; 5:e279-86.

5. Saunders GL, Lipman J, Klugman K. Invasive candidiasis in the ICU--pathogenesis and management strategy. S Afr J Surg 1994; 32:154-6.

6. van de Veerdonk FL, Kullberg BJ, Netea MG. Pathogenesis of invasive candidiasis. Curr Opin Crit Care 2010;16:453-9.

7. Sherwood-Higham J, Zhu WY, Devine CA, Gooday GW, Gow NA, Gregory DW. Helical growth of hyphae of Candida albicans. J Med Vet Mycol 1994;32:437-45.

8. Sevilla MJ, Odds FC. Development of Candida albicans hyphae in different growth media--variations in growth rates, cell dimensions and timing of morphogenetic events. J Gen Microbiol 1986;132:3083-8.

9. Sudbery PE. Growth of Candida albicans hyphae. Nat Rev Microbiol 2011;9:737-48.

10. Shareck J, Belhumeur P. Modulation of morphogenesis in Candida albicans by various small molecules. Eukaryot Cell 2011;10:1004-12.

11. Bulad K, Taylor RL, Verran J, McCord JF. Colonization and penetration of denture soft lining materials by Candida albicans. Dent Mater 2004;20:167-75.

12. Budtz-Jörgensen E, Stenderup A, Grabowski M. An epidemiologic study of yeasts in elderly denture wearers. Community Dent Oral Epidemiol 1975;3:115-9.

13. Jackson S, Coulthwaite L, Loewy Z, Scallan A, Verran J. Biofilm development by blastospores and hyphae of Candida albicans on abraded denture acrylic resin surfaces. J Prosthet Dent 2014;112:988-93.

14. Edgerton M, Raj PA, Levine MJ. Surface-modified poly(methyl methacrylate) enhances adsorption and retains anticandidal activities of salivary histatin 5. J Biomed Mater Res 1995;29: 1277-86.

15. Assunção WG, Barão VA, Pita MS, Goiato MC. Effect of polymerization methods and thermal cycling on color stability of acrylic resin denture teeth. J Prosthet Dent 2009;102:385-92.

16. Hong G, Murata H, Li Y, Sadamori S, Hamada T. Influence of denture cleansers on the color stability of three types of denture base acrylic resin. J Prosthet Dent 2009;101:205-13.

17. Gregorius WC, Kattadiyil MT, Goodacre CJ, Roggenkamp CL, Powers JM, Paravina RD. Effects of ageing and staining on color of acrylic resin denture teeth. J Dent 2012;40 Suppl 2:e47-54.

18. Nikawa $H$, Hamada T, Yamashiro $H$, Kumagai $H$. A review of in vitro and in vivo methods to evaluate the efficacy of denture cleansers. Int J Prosthodont 1999;12:153-9.

19. Budtz-Jørgensen E. Materials and methods for cleaning dentures. J Prosthet Dent 1979;42:619-23.

20. Davi LR, Peracini A, Ribeiro Nde Q, Soares RB, da Silva CH, Paranhos Hde F, et al. Effect of the physical properties of acrylic resin of overnight immersion in sodium hypochlorite solution. Gerodontology 2010;27:297-302.

21. Peracini A, Davi LR, de Queiroz Ribeiro N, de Souza RF, Lovato da Silva CH, de Freitas Oliveira Paranhos H. Effect of denture cleansers on physical properties of heat-polymerized acrylic resin. J Prosthodont Res 2010;54:78-83.

22. Davi LR, Felipucci DN, de Souza RF, Bezzon OL, Lovato-Silva $\mathrm{CH}$, Pagnano VO, et al. Effect of denture cleansers on metal ion release and surface roughness of denture base materials. Braz Dent J 2012;23:387-93.

23. Azevedo A, Machado AL, Vergani CE, Giampaolo ET, Pavarina AC, Magnani R. Effect of disinfectants on the hardness and 
roughness of reline acrylic resins. J Prosthodont 2006;15:235-42.

24. McNeme SJ, von Gonten AS, Woolsey GD. Effects of laboratory disinfecting agents on color stability of denture acrylic resins. J Prosthet Dent 1991;66:132-6.

25. Moore TC, Smith DE, Kenny GE. Sanitization of dentures by several denture hygiene methods. J Prosthet Dent 1984;52:158-63.

26. Gornitsky M, ParadisI I, Landaverde G, Malo AM, Velly AM. A clinical and microbiological evaluation of denture cleansers for geriatric patients in long-term care institutions. J Can Dent Assoc 2002;68:39-45.

27. Pyo KY, Yoo YS, Baek DH. Antifungal effect of electrolyzed hydrogen water on Candida albicans biofilm. J Dent Rehabil Appl Sci 2015;31:212-20.

28. Rupp S. Interactions of the fungal pathogen Candida albicans with the host. Future Microbiol 2007;2:141-51.

29. Dellinger TM, Livingston HM. Oral candidiasis. Ann Pharmacother 2003;37:1529.

30. Hawser SP, Douglas LJ. Biofilm formation by Candida species on the surface of catheter materials in vitro. Infect Immun 1994;62:915-21.

31. Douglas LJ. Candida proteinases and candidosis. Crit Rev Biotechnol 1988;8:121-9.

32. Blankenship JR, Mitchell AP. How to build a biofilm: a fungal perspective. Curr Opin Microbiol 2006;9:588-94.

33. Cakan U, Kara O, Kara HB. Effects of various denture cleansers on surface roughness of hard permanent reline resins. Dent
Mater J 2015;34:246-51.

34. Durkan R, Ayaz EA, Bagis B, Gurbuz A, Ozturk N, Korkmaz FM. Comparative effects of denture cleansers on physical properties of polyamide and polymethyl methacrylate base polymers. Dent Mater J 2013;32:367-75.

35. Jin C, Nikawa H, Makihira S, Hamada T, Furukawa M, Murata $\mathrm{H}$. Changes in surface roughness and colour stability of soft denture lining materials caused by denture cleansers. J Oral Rehabil 2003;30:125-30.

36. Huh JB, Lim Y, Youn HI, Chang BM, Lee JY, Shin SW. Effect of denture cleansers on Candida albicans biofilm formation over resilient liners. J Adv Prosthodont 2014;6:109-14.

37. Saraç D, Saraç YS, Kurt M, Yüzbaşioğlu E. The effectiveness of denture cleansers on soft denture liners colored by food colorant solutions. J Prosthodont 2007;16:185-91.

38. Porwal A, Khandelwal M, Punia V, Sharma V. Effect of denture cleansers on color stability, surface roughness, and hardness of different denture base resins. J Indian Prosthodont Soc 2017; 17: 61-7.

39. Haghi HR, Asadzadeh N, Sahebalam R, Nakhaei M, Amir JZ. Effect of denture cleansers on color stability and surface roughness of denture base acrylic resin. Indian J Dent Res 2015;26: 163-6.

40. Silva PM, Acosta EJ, Jacobina M, Pinto Lde R, Porto VC. Effect of repeated immersion solution cycles on the color stability of denture tooth acrylic resins. J Appl Oral Sci 2011;19:623-7. 